\section{Droplet Spreading: varying viscosity}

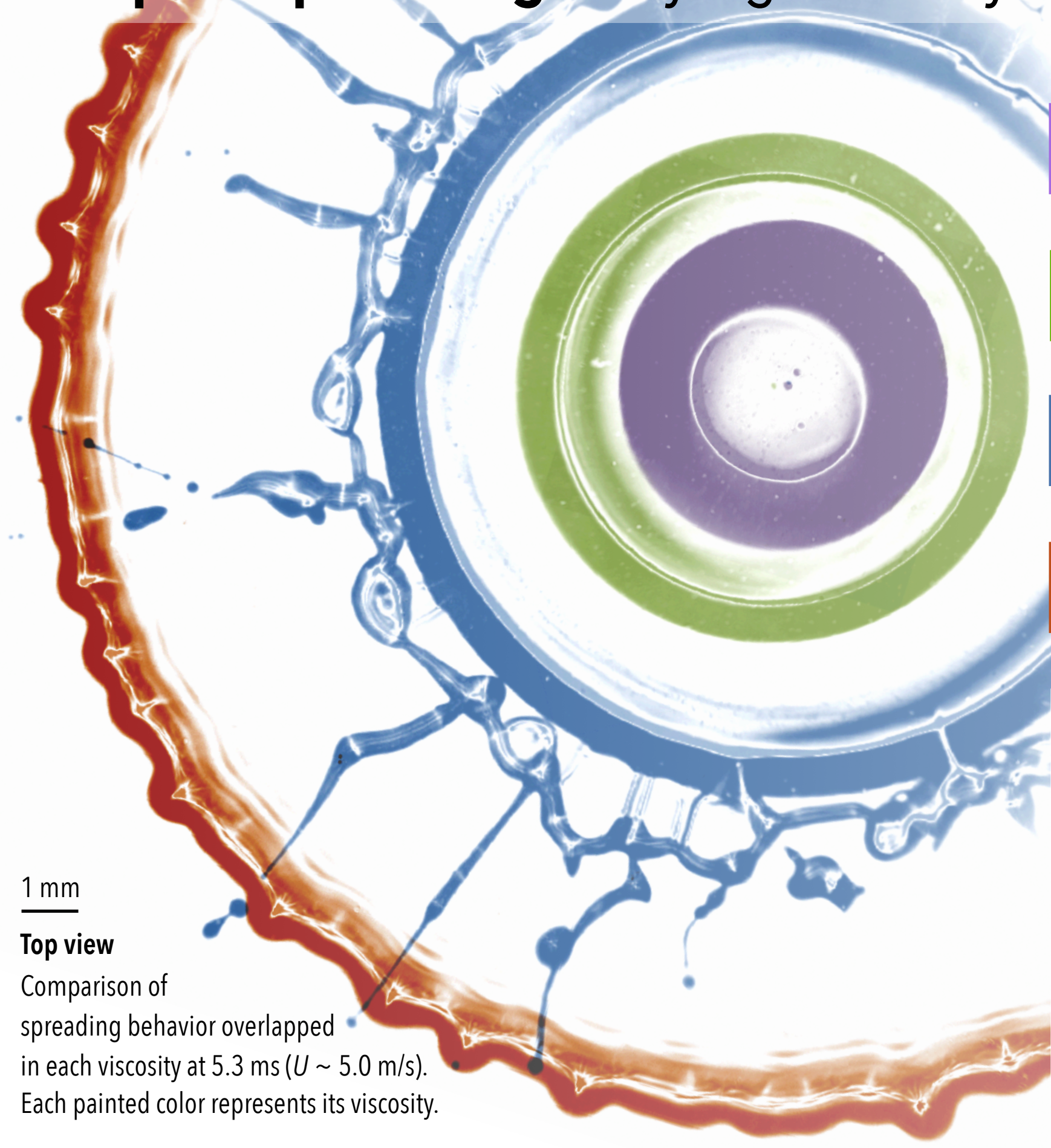

Y. Fujita, N. Endo, S. Kawamoto, A. Kiyama \& Y. Tagawa Tokyo University of Agriculture and Technology

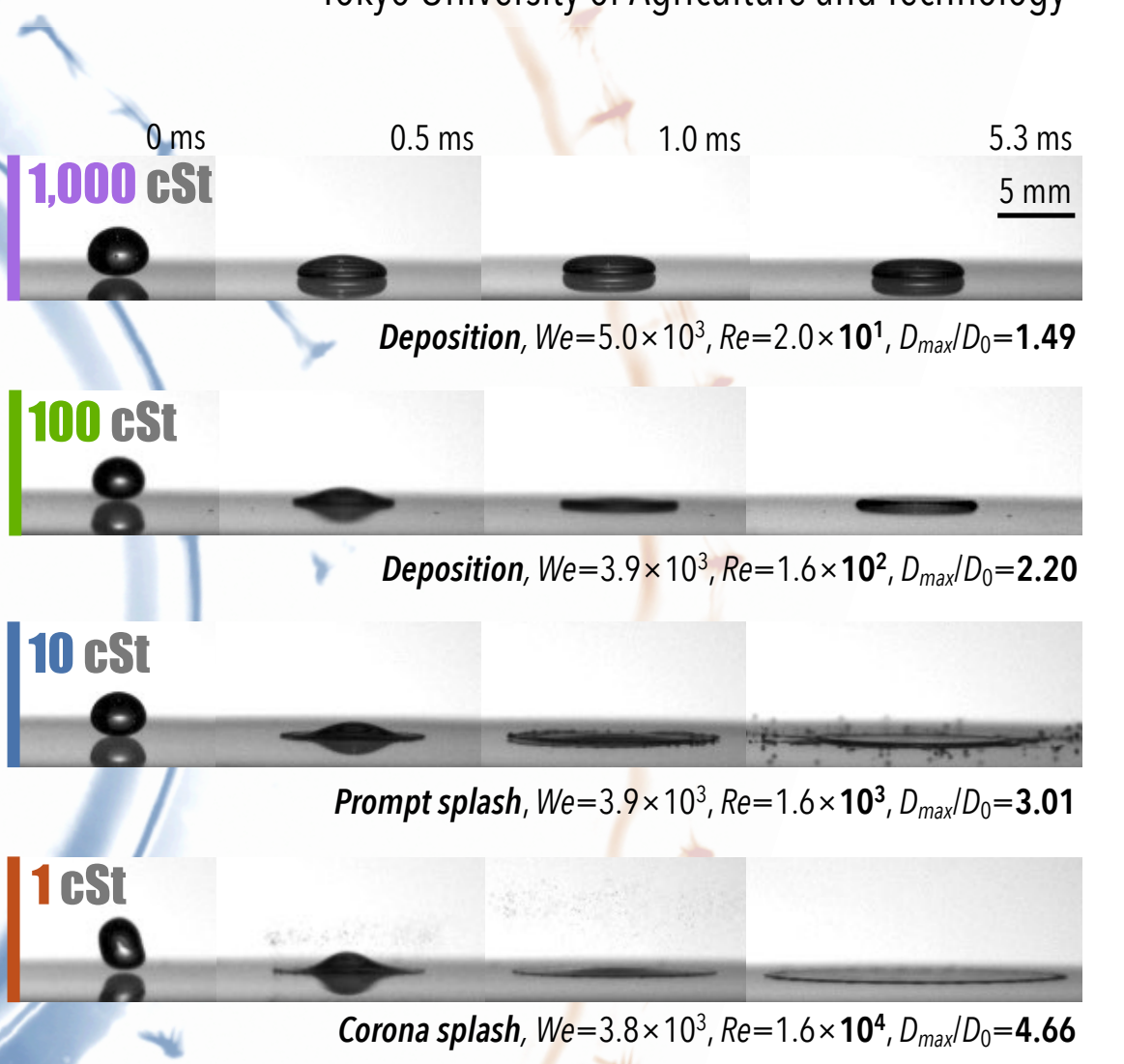

roplet spreading on a glass surface is recorded by two synchronized high-speed cameras. Viscosity of droplet is varied from 1 to $1,000 \mathrm{cSt}$. As shown in upperright panels, the flow pattern is obviously varied from Deposition to Splash ${ }^{\star 1}$ (see also main picture). Impact velocity is almost the constant, thus dominant parameter here is Reynolds number $R e$ (namely, viscous force). For the maximal deformation of an impacting droplet, $D_{\max } / D_{0}$, viscous force plays an important role as well. The impact number $P$, which is the measure of the ratio of the capillary force and the viscous force formulated as We/Re $e^{0.8}$, is larger than 1 for all conditions. It means that the description by capillary force no longer holds. A scaling law $D_{\max } \propto D_{0} R e^{0.2}$, which takes viscous effect into account, should be adopted instead ${ }^{\star 2,}{ }^{* 3}$.

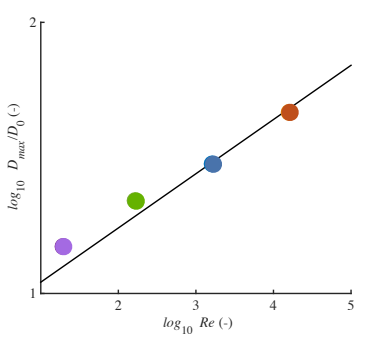

References: ${ }^{\star 1}$ YARIN, A. L. (2006), ${ }^{*}$ CLANET, C., et al. (2004), ${ }^{\star 3}$ EGGERS, J. et al. (2010) 